\title{
Metafora Asa - Burung Sriti untuk Rehabilitasi Mental Anak Korban Kekerasan
}

\author{
Terri Mayangsari Yunus dan Rullan Nirwansjah \\ Departemen Arsitektur, Fakultas Teknik Sipil dan Perencanaan, Institut Teknologi Sepuluh Nopember (ITS) \\ e-mail: rullan@arch.its.ac.id
}

\begin{abstract}
Abstrak-Kekerasan terhadap anak di kota Surabaya dan sekitarnya semakin meningkat setiap tahunnya. Sering sekali penyelesaian masalah terhenti pada tahapan pengobatan fisik saja tanpa mempertimbangkan kerusakan psikis yang diterima anak selaku korban. Untuk itu, dibutuhkan terapi penyembuhan dan kenyamanan, serta keamanan yang sangat diperlukan untuk menunjang penyembuhan psikis anak. Dengan demikian dibutuhkan fasilitas dengan desain yang dapat menampung semua kebutuhan tersebut dengan baik. Desain yang sesuai adalah yang dapat meningkatkan secara maksimal kemampuan korban agar kejadian yang sama tidak berulang dan mencegah tindakan berbahaya yang dapat dilakukan korban akibat efek psikologis dari kekerasan tersebut. Pasien atau anak harus dapat menemukan kembali harapan hidupnya yang seakan hilang karena tindak kekerasan tersebut. Untuk itu digunakan konsep asa; harapan atau hope, yang dapat dijabarkan lagi menjadi burung sriti sebagai simbol asa yang telah terbukti mengurangi tingkat depresi seseorang, untuk dimetaforakan kedalam karya arsitektur.
\end{abstract}

Kata Kunci-Anak, Asa, Burung Sriti, Hope, Kekerasan, Rehabilitasi.

\section{PENDAHULUAN}

A NAK adalah seseorang yang belum berumur 18 tahun, yang merupakan amanah dan karunia Tuhan yang berhak untuk hidup, tumbuh dan berkembang secara maksimal sesuai potensinya. Sayangnya, hak-hak tersebut tidak dimiliki beberapa anak karena terjadinya hal yang menghambat potensi mereka, seperti tindakan kekerasan.

Data Survei Kekerasan terhadap Perempuan dan Anak Tahun 2006 mencatat bahwa setiap 10.000 anak Indonesia sekitar 302 anak pernah mengalami kekerasan, dengan total jumlah 2,29 juta anak. Sekitar 1,23 juta jiwa di antaranya adalah anak laki-laki dan 1,06 juta jiwa adalah anak perempuan [1]. Perbandingan persentase sesuai jenis kelamin dapat dilihat pada gambar 1. Berdasarkan publikasi Jawa Pos 2015, untuk bulan Januari hingga Agustus 2015 saja, sudah terdeteksi 290 kasus kekerasan terhadap anak, dimana sebagian besar merupakan kekerasan seksual. Berdasarkan tempat kejadian, kota Surabaya masih menempati peringkat teratas kekerasan terhadap anak yang mencapai 153 kasus, diikuti Mojokerto 36 kasus, Gresik 31 kasus, Jombang 22 kasus, dan Lamongan 21 kekerasan terhadap anak sebesar 18 persen dari total kasus di Jatim. Sebanyak 47 di antara 153 kasus di Surabaya merupakan kasus kekerasan dan pelecehan seksual [2].
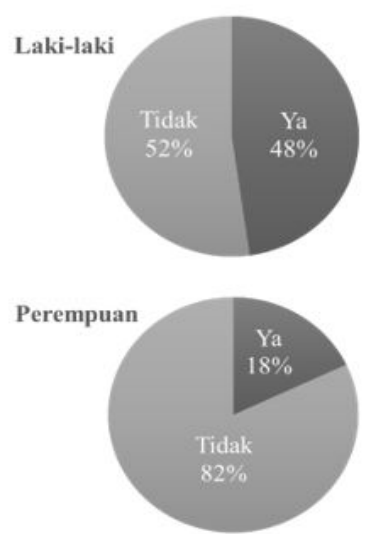

Gambar 1. Prevalensi Kekerasan (seksual, fisik dan emosional) yang dialami Laki-laki dan Perempuan kelompok umur 18-24 tahun, sebelum umur 18 tahun [3].

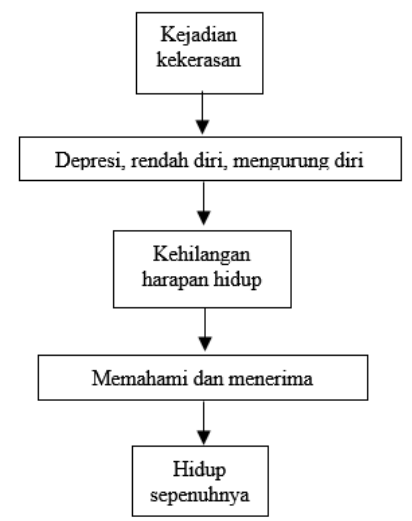

Gambar 2. Diagram kondisi mental anak pasca kekerasan.

Dalam penanganan masalah ini, pemerintah telah menyediakan RPSA (Rumah Perlindungan Sosial Anak). Sayangnya, adanya fasilitas ini tidak diimbangi dengan desain bangunan yang dapat membantu pemulihan kesehatan mental seseorang, terlebih seorang anak, yang biasanya mengalami depresi dan putus asa dalam hidup. Oleh karena itu, dibutuhkan suatu ruang yang memasukkan unsur yang dapat mengembalikan asa seorang anak seperti semula yang juga membantu mempermudah proses penyembuhan untuk anak, yaitu dengan memetaforakan bangunan sebagai kata asa dan mengaitkan unsur arsitektural seperti cahaya dan lansekap yang merupakan salah satu unsur penyembuhan mental seseorang, tanpa melupakan konteks pengguna yaitu anak. 


\section{EKSPLORASI DAN PROSES RANCANG}

Untuk mempengaruhi kondisi seseorang, pendekatan arsitektur yang digunakan merupakan arsitektur perilaku. Pendekatan perilaku menekankan pada keterkaitan antara ruang dengan manusia dan masyarakat yang memanfaatkan ruang atau menghuni ruang tersebut. Dengan kata lain pendekatan ini melihat aspek norma, kultur, masyarakat yang berbeda akan menghasilkan konsep dan wujud ruang yang berbeda (Rapoport, 1969) [4]. Dengan adanya interaksi antara manusia dan ruang, maka pendekatannya cenderung menggunakan setting dari pada ruang, yang lebih memberikan penekanan pada unsur-unsur kegiatan manusia yang mengandung empat hal yaitu pelaku, macam kegiatan, tempat dan waktu berlangsungnya kegiatan.

Pendekatan yang juga digunakan adalah dari bidang psikologi. Menurut bidang ini, cara untuk membantu mempengaruhi kondisi mental seseorang, adalah dengan tindakan psikoterapi. Menurut Snyder, Irving \& Anderson (1991), harapan, atau asa, adalah suatu mekanisme dalam psikoterapi. Asa digunakan sebagai jalan untuk mengatasi kurangnya motivasi seseorang untuk mencapai tujuannya. Asa, menurut Snyder, juga dianggap sebagai suplemen dari terapi perilaku [5].

A. Metode

Gambar 3. Ilustrasi burung Sriti (rspb.org.uk, diakses 21 Maret 2016).

Tabel 1.

Aplikasi Metode Metafora dalam Desain Metafora Intangible

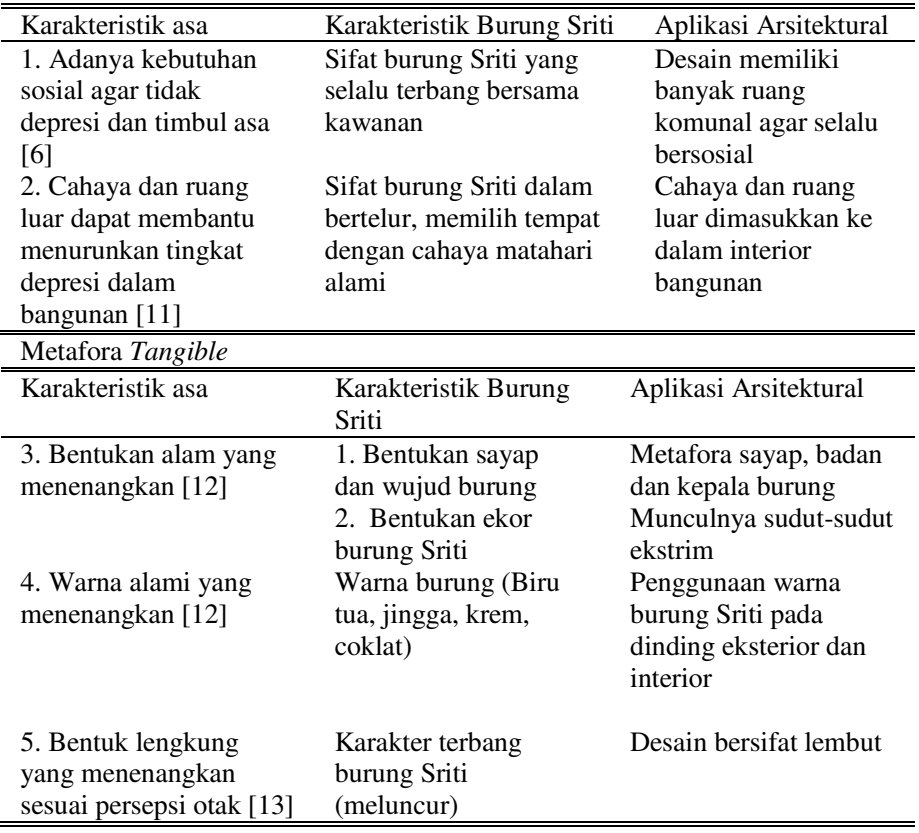

Untuk memunculkan harapan; atau asa dalam pengguna (anak), maka dipilihlah metode metafora yang mengkaitkan arsitektur dengan bahasa yang digagas oleh Jenks (1977) [7]. Dengan cara ini, kiasan atau ungkapan bentuk, diwujudkan dalam bangunan dengan harapan akan menimbulkan tanggapan dari orang yang menikmati atau memakai karyanya. Prinsip- prinsip Metafora antara lain adalah dengan mencoba atau berusaha memindahkan keterangan dari suatu subjek ke subjek lain, serta mencoba atau berusaha untuk melihat suatu subjek seakan-akan sesuatu hal yang lain. Dalam hal ini, kondisi yang diinginkan adalah agar anak yang depresi dan putus asa akan kehidupannya akan kembali ceria dan optimistis. Maka dari itu, kata asa adalah kunci dari desain bangunan yang diinginkan.

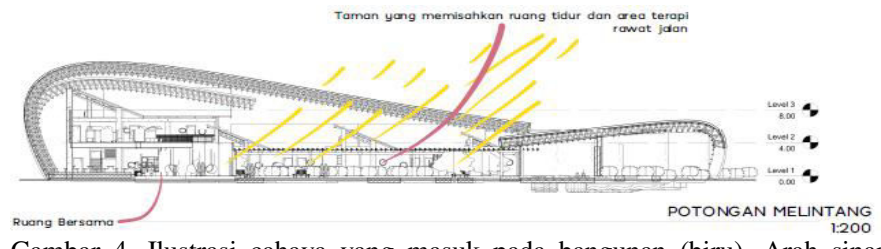

Gambar 4. Ilustrasi cahaya yang masuk pada bangunan (biru). Arah sinar matahari digambarkan dengan garis berwarna kuning. (Dok. Pribadi).

\section{B. Aplikasi Metode}

Menurut KBBI, asa merupakan kata benda yang berarti harap(an) dan semangat. Kata 'harap' memiliki artian mohon, minta, hendaklah, sehingga kata harapan berarti sesuatu yang dapat diharapkan, keinginan supaya menjadi kenyataan, dan orang yang diharapkan atau dipercaya [8]. Berdasarkan analisa pengertian yang ada di atas, kata 'asa' atau 'harapan' muncul agar sesuatu yang tidak ada menjadi ada; yang tidak terjadi agar terjadi; dan hal-hal lainnya yang bersifat kontras. Bagi anak korban kekerasan, hal yang menyenangkan, menenangkan, menjaganya dari kekerasan dapat membantu mereka melupakan peristiwa tersebut dan menjadikan ia kembali memiliki semangat hidup.

\section{Konsep Desain}

Burung Sriti (gambar 3) merupakan simbol asa oleh berbagai kalangan, seperti pelaut [9] dan masyarakat Eropa [10]. Selain itu, karakter yang menggambarkan harapan akan kehidupan lebih baik yang ingin dimunculkan kembali dalam diri anak korban kekerasan. Oleh karena itu Asa dan burung sriti dijadikan tema utama dari penerapan metode metafora tangible dan intangible. Berikut adalah telaah Asa dan karakter burung sriti serta aplikasi metaforanya dalam arsitektur. (tabel 1)

\section{HASIL RANCANGAN}

\section{A. Tatanan Massa}

Tatanan massa bangunan terbentuk melalui analisa kebutuhan ruangan dan kebutuhan cahaya matahari alami pada tiap ruang sesuai jadwal kegiatan terapi pengguna, serta lansekap pada ruang bangunan, untuk memenuhi kriteria pada tabel 1, poin 2, dengan memperhatikan poin 3. Diagram transformasi bentuk metafora burung Sriti (poin 3) menuju tatanan massa bangunan (gambar 4). 

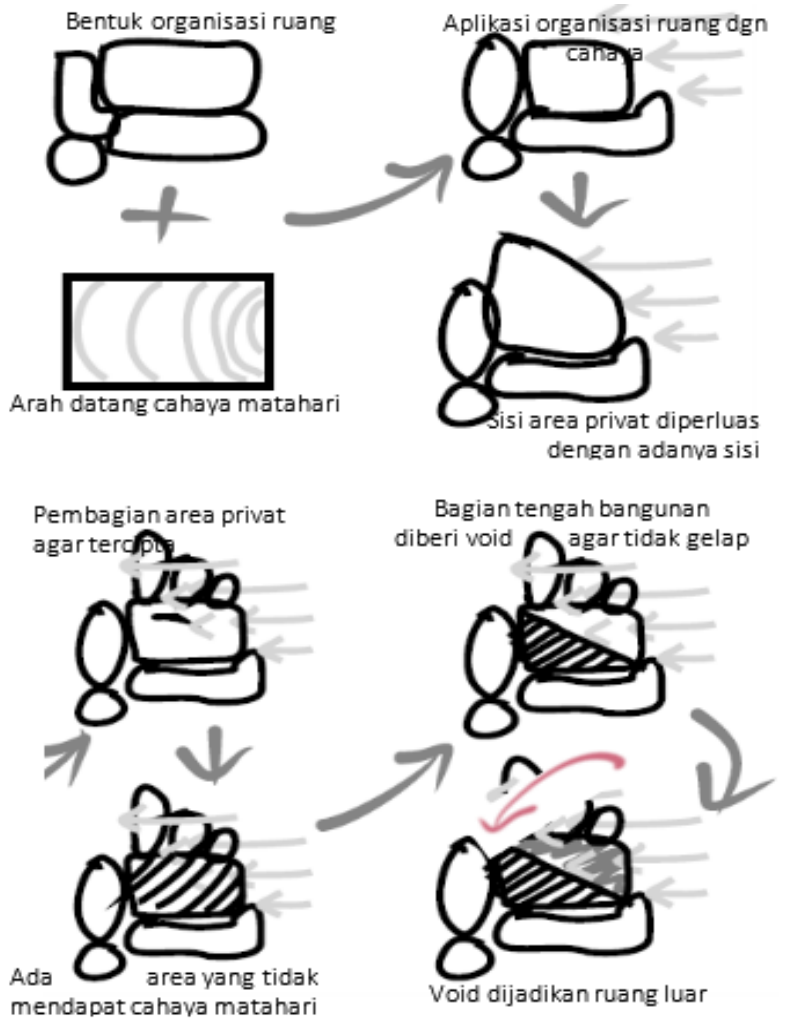

Gambar 5. Transformasi bentuk burung Sriti ke tatanan massa bangunan (Dok. Pribadi)

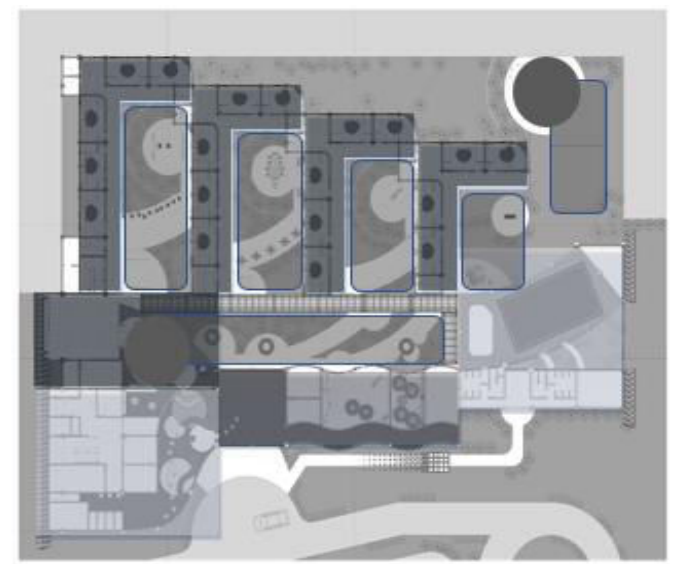

Gambar 6. Layout plan dengan penanda $(1=$ area staf, $3=$ area anak rawat jalan, $4=$ area umum, $2=$ area residen anak, $5=$ taman. (Dok. Pribadi).

Dengan menggunakan arah datang cahaya matahari, terbentuklah tatanan massa seperti dipada gambar 4, dengan hasil aplikasi pada gambar 5. Selain itu, bentuk tatanan massa juga menciptakan ruang luar yang cukup untuk masing-masing ruang dalam (gambar 6)

1) Area Staf

Massa ini dapat dimetaforakan sebagai kepala burung, dengan lengkung dan ketinggiannya yang mencapai 3 lantai. Adanya void dibagian lobby menguatkan kesan mengundang, dan massa ini berada didepan sebagai 'otak' dalam suatu pergerakan burung, seperti penggunanya

2) Area Residen Anak Inap

Massa bangunan yang dipergunakan untuk ruang tidur anak dapat dimetaforakan seperti sayap burung. Bentuk tatanan massa ini terjadi karena adanya kebutuhan cahaya per ruangan dan adanya kebutuhan akan banyaknya ruang komunal pada bangunan, agar menciptakan interaksi sosial kepada penggunanya.

Dapat dilihat pada gambar diatas bahwa terdapat 4 massa bangunan untuk ruang tidur. Hanya 1 dari 4 massa tersebutmemiliki ketinggian 2 lantai, lebih pendek dari ruang lainnya. Hal ini terjadi karena ruang yang terlalu tinggi dan tidak proporsional dengan luasnya dapat menyebabkan efek psikologis yang tidak diinginkan dalam bangunan ini. Selain itu, juga dapat diperhatikan bahwa setiap massa nya ditentukan untuk kategori umur dan gender masing-masing anak, sebagai pemisah. Hal ini juga dengan perbedaan jenis permainan yang ada di terletak di depan ruang tidur mereka masing-masing

\section{3) Area Anak Rawat Jalan}

Dari bentuknya, massa ini dapat dimetaforkan seperti badan burung, yang sudah lebih kuat dari sayap, seperti penggunanya yang kondisinya lebih baik daripada residen inap. Massa bangunan yang diperuntukkan untuk pasien anak rawat jalan berada di depan, dipisahkan oleh taman, antara ruang tidur atau zona residen. Adanya taman dan lokasinya yang berada di depan dapat berguna sebagai pembatas bagi zona residen yang privat, serta dapat memudahkan penggunanya melihat ke ruang luar, dan memperbesar kemungkinan adanya sinar matahari yang masuk. Selain itu massa ini memiliki banyak lengkung, yang juga memenuhi kriteria desain pada tabel 1 poin 5.

\section{4) Area Umum}

Massa yang diperuntukkan untuk masyarakat umum dimetaforakan dengan bentukan ekor sriti. Di area inilah, masyarakat dapat berperan penting dalam mengajarkan sosialisasi kembali kepada anak.

\section{B. Fasad}

Fasad bangunan dimetaforakan dari bentukan kasar sayap burung yang sedang terbang dan mengepakkan sayap, mengacu pada kriteria desain pada tabel 1 poin 3. Bentukan ini, walaupun dasarnya adalah bentuk segitiga, namun tidak memiliki sudut lancip. Hal ini terjadi agar bangunan terkesan lembut dan melindungi, serta memenuhi poin 5 pada tabel 1 .

\section{Ruang Luar}

Lansekap dalam bangunan terbagi menjadi beberapa bagian, yaitu lansekap area parkir, area residen inap, area sosial, serta area umum.

\section{1) Lansekap Area Residen Inap}

Pada area residen anak, pengguna dipisahkan secara gender, umur, dan tingkat kesiapan untuk kembali hidup di masyarakat. Hal ini diakomodasi dengan adanya lansekap yang sesuai dengan kebutuhannya. Contohnya, pada lansekap paling dekat dengan zona staf, permainan yang ada adalah kuda-kudaan. Secara gradual, furnitur lanskap yang ada semakin menyiratkan mental seorang yang tinggal di massa tersebut (gambar 11.a, 11.b). Sebagai perbandingan, lanskap atau taman yang terletak paling jauh hanya dilengkapi gazebo 
dan permainan air, karena letaknya yang juga dekat dengan kolam renang.

\section{Lansekap Area Sosial}

Pada lansekap yang memisahkan antara ruang tidur dan ruang terapi pasien rawat jalan, lebih difokuskan untuk kegiatan bercengkerama antara satu dengan yang lain dan memasukkan cahaya matahari alami ke dalam ruang utama (gambar 10).

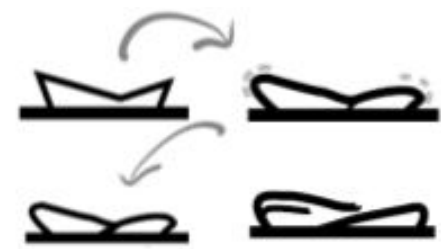

Gambar 7. Transformasi bentuk burung dengan fokus sayap menuju bentuk fasad bangunan (Dok. Pribadi).

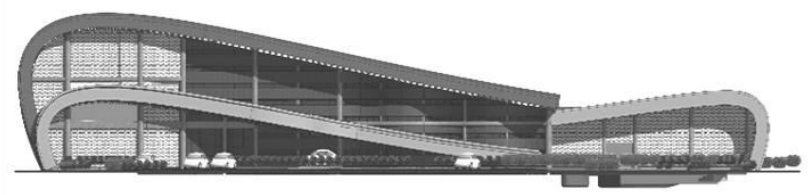

Gambar 8. Tampak depan bangunan (Dok. Pribadi)

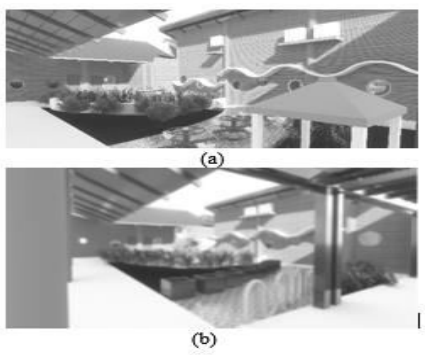

Gambar 9. Ilustrasi Perspektif Lansekap Area Residen Inap (Dok. Pribadi).

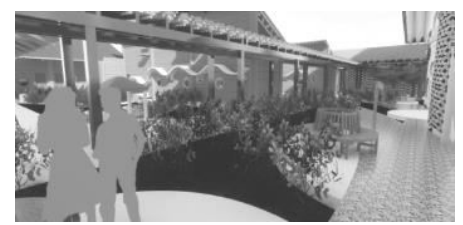

Gambar 10. Perspektif Lansekap Area Sosial (Dok. Pribadi).

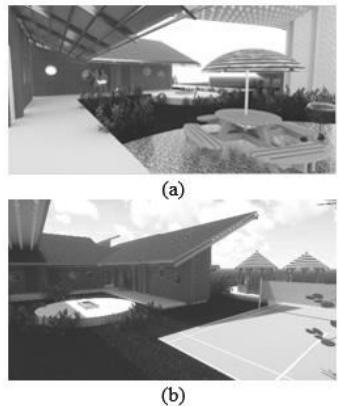

Gambar 11. Ilustrasi Perspektif Lansekap Area Umum (Dok. Pribadi).

\section{2) Lansekap Area Umum}

Pada area ini, para pengunjung dan pengantar yang menggunakan fasilitas kolam renang dan yang menunggu anak atau kerabatnya dapat bertemu dan bersosialisasi dengan residen yang tidur di area tersebut, yaitu yang sudah dianggap siap untuk re-sosialisasi sebagai salah satu bagian dari terapi. (gambar 13).

\section{Ruang Dalam}

\section{1) Lobby}

Lobby (gambar 12) berada di zoning staff yang berada di depan, didominasi dengan bentuk kaca luar yang melengkung. Bentukan yang berbeda dari denah lainnya ini dianggap dapat memperjelas fungsinya sebagai entrance. Selain itu, lobby ini juga memiliki ketinggian langit-langit masif yang mengundang. Penggunaan warna dingin seperti biru dan hitam dapat menenangkan anak, tanpa memberi kesan institusional sehingga tetap ada kesan warna-warni di dinding dan karpet.

2) Ruang Terapi

Di ruang terapi, dinding didominasi dengan bentuk lengkung. Pada ruang terapi rekreasi/bermain (gambar 13), dapat ditemukan area panjat tebing kecil yang memanfaatkan ketinggian atap yang dapat menjadi sarana terapi untuk anak yang lebih dewasa, dan seluncuran untuk anak yang lebih kecil.

Rekreasi/Bermain dan ruang terapi grup dan seni (gambar 14), selain juga didominasi dinding lengkung, juga memiliki tembok yang dilapisi dengan cat untuk papan tulis hitam di seluruh bagiannya. Kesan gelap ditepis dengan adanya lantai berwarna-warni, serta tembok yang harapannya akan digambar oleh masing-masing anak sehingga kemudian hari akan menjadi lebih berwarna.

\section{3) Ruang Sosial}

Ruang sosial dalam suatu fasilitas sejenis biasanya terbagi menjadi dua, ramai dan berisik. Kedua ruang sosial ini terpisahkan oleh ketinggian, dimana ruang sosial ramai berada tepat di bawah ruang sosial sunyi. Keputusan ini muncul karena pada lantai dasar, kebisingan lebih dapat dirasakan, terlebih letaknya yang dekat dengan zona staf.

Ruang sosial ramai (gambar 15) terletak sejajar dengan ruang makan. Bentuk ruangan lengkung dan adanya kaca sebagai pemisah antara ruang dengan lansekap luar juga dapat memasukkan sinar matahari. Warna yang digunakan dalam ruangan sosial adalah warna-warna yang terkesan hangat, seperti hijau, kuning, dan merah yang menstimulasi kegiatan sosial dan juga selera makan anak. Pada ruang sosial sunyi (gambar 18), bentuk ruang juga sama dengan ruang sosial ramai.

\section{4) Kamar Tidur}

Area kamar tidur memiliki view lansekap di jendela depan maupun jendela belakang. Area ini didominasi oleh penggunaan material alami seperti kayu yang terbukti menurunkan tingkat depresi seseorang. Setiap kamar diperuntukkan untuk 2 orang. 


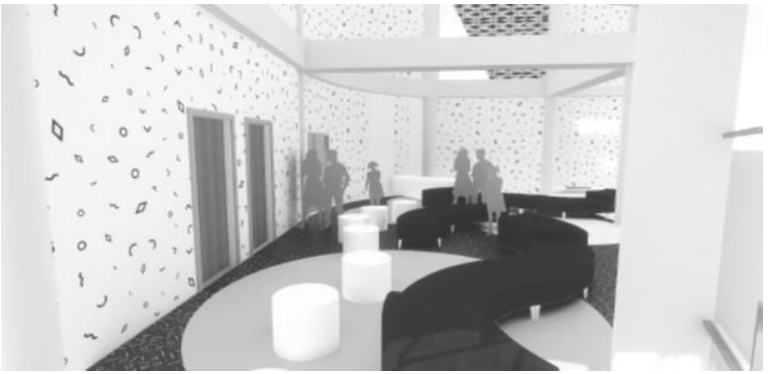

Gambar 12. Perspektif Interior Ruang Lobby (Dok. Pribadi).

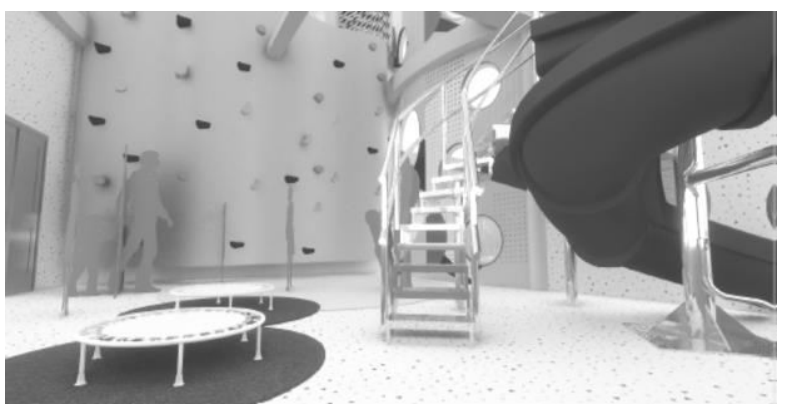

Gambar 13. Perspektif Interior Ruang Terapi (Dok. Pribadi).

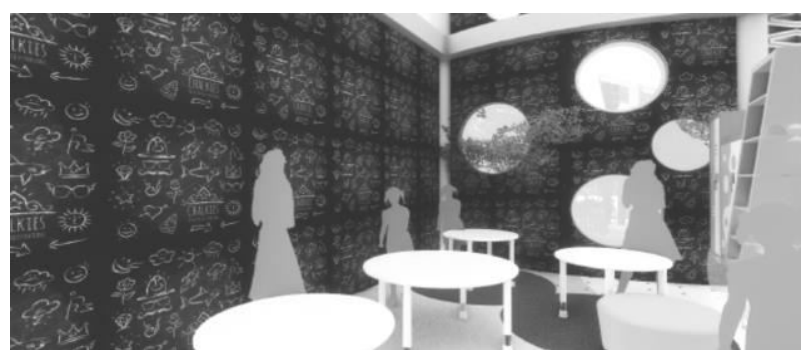

Gambar 14. Perspektif Interior Ruang Terapi Grup/Seni (Dok. Pribadi).

\section{KESIMPULAN}

Obyek arsitektur dirancang agar dapat membantu menyembuhkan efek dari kekerasan yang terjadi terhadap anak, agar sang anak dapat melanjutkan hidupnya seperti anak-anak pada umurnya. Adanya bangunan ini tentu tidak serta-merta menghilangkan kenangan akan kejadian kekerasan tersebut, namun dengan berbagai studi dan aspek, bangunan ini diharapkan dapat membantu agar tingkat kesehatan mental suatu anak tidak menurun, dan menjadi lebih baik. Obyek dirancang dengan metode metafora dan berbagai aspek non arsitektural serta pendekatan perilaku yang terbukti menjaga kesehatan mental seseorang menjadi terjaga dan lebih baik.

\section{DAFTAR PUSTAKA}

Kementerian Negara Pemberdayaan Perempuan, "Fenomena Tindak Kekerasan Terhadap Perempuan dan Anak," 2006.

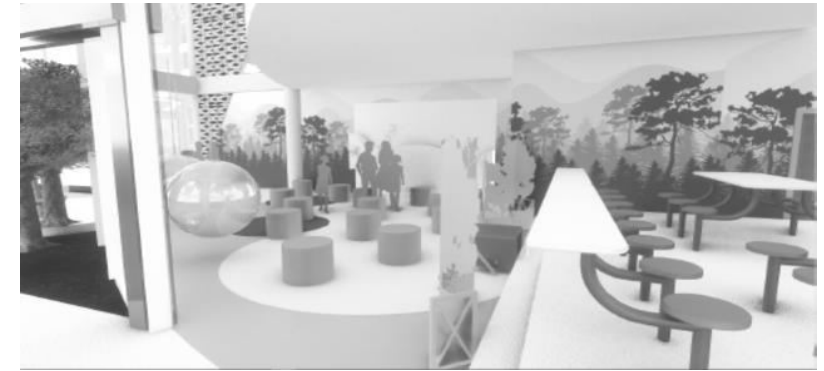

Gambar 15. Perspektif Interior Ruang Sosial Ramai (Dok. Pribadi).

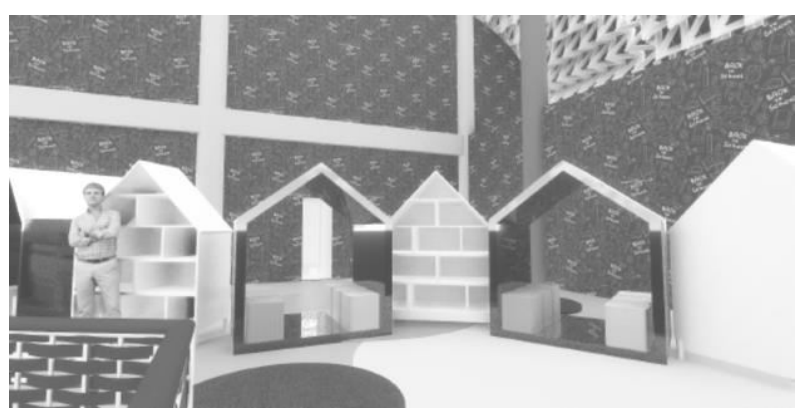

Gambar 16. Perspektif Interior Ruang Sosial Sunyi (Dok. Pribadi).

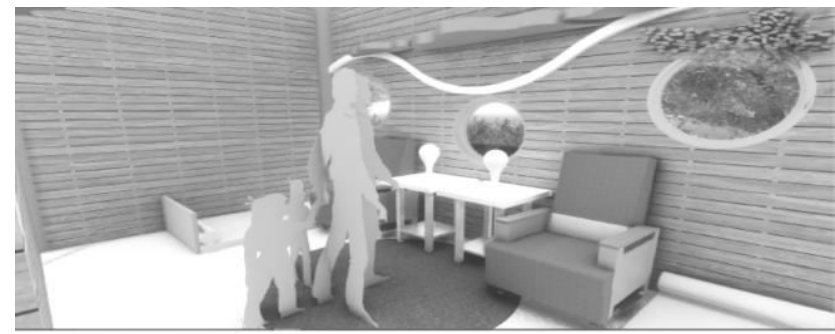

Gambar 17. Perspektif Interior Kamar Tidur (Dok. Pribadi).
[2]

[3]

[6]

(6)

Kementerian Sosial, "Survey Kekerasan Terhadap Anak Indonesia," 2013

Surabayanews, "Surabaya Tertinggi Kasus Kekerasan Anak," 2015. A. Rapoport, House Form and Culture. New Jersey: Prentice Hal, Inc, 1969.

C. R. Snyder, J. R. Anderson, and L. M. Irving, "The will and the ways: Development and validation of an individual-differences measure of hope," J. Pers. Soc. Psychol., vol. 60, no. 4, 1991. www.hopkinschildrens.org, "Depression, Lack of Social Support Trigger Suicidal Thoughts in College Students." [Online]. Available: http://www.hopkinschildrens.org/Depression-Lack-ofSocial-Support-Trigger-Suicidal-Thoughts-in-College-

Students.aspx. [Accessed: 25-Jan-2017].

C. Jencks, The Language of Post-Modern Architecture. Rizzoli, 1977.

kbbi.web.id, "Asa." [Online]. Available: http://kbbi.web.id/asa. tattoou.net, "Swallow Tattoo Meanings." [Online]. Available: https://tattoou.net/meaning/swallow.

outre-monde.com, "The Psychology and Philosophy of Hope," 2014. [Online]. Available: https://outre-monde.com/2014/11/10/thepsychology-and-philosophy-of-hope/. [Accessed: 22-Jan-2017]. 